\title{
Policy Bundling and Costly Monitoring
}

\author{
Greg Sasso*
}

March 18, 2021

\begin{abstract}
When should elected officials be in charge of multiple vs single policy areas? To study this question, I analyze a formal model of political accountability where politicians can have authority over one or two policy areas. When all politicians act sincerely, voters are always better off with unbundled policies. However, the voter is indifferent when all politicians pander. When bundled politicians partially-pander, the optimal institution is dependent on how likely the politician is to be a good type. I then show that voters are willing to spend more to monitor politicians in charge of multiple policy areas.
\end{abstract}

*Emory University, Email: gregory.sasso@emory.edu 


\section{Introduction}

When is having one elected official better than two? One view is that there is more democratic accountability with more elected officials. Voters can more accurately assign credit and blame when elected officials are in charge of small, specific policy areas. However, monitoring multiple officials is costly, and therefore may lead to lower accountability because voters will not pay attention and or not vote. This is particularly salient in U.S. local elections, where there are often multiple overlapping jurisdictions with separate elections and elected officials. For example, school boards, water reclamation districts, transit districts and others can all have their own elections in addition to mayoral elections.

In addition, elections are costly for voters. This cost is seen in ballot roll off (the phenomenon where voters will fill in their ballot for more prominent races and leave less prominent races blank). ${ }^{1}$ Local election turnout is also an example of election cost biting. When local elections such as school board elections are scheduled non-concurrently with major elections, the local elections experience lower turnout (Berry and Gersen 2010).

Ballot rolloff and low turnout have significant policy implications. Anzia (2011, 2013); Berry and Gersen (2010) show that off-cycle elections lead to more interest group capture. In addition, (Berry 2009) finds that areas with many overlapping local jurisdictions are associated with over taxation when compared to areas with fewer jurisdictions.

These empirical facts establish that there certainly can be too many elected officials; however, they do not tell us in which situations have more officials is better than having fewer or vice versa. For example, it can be the case Illinois has too many jurisdictions (the most in the country according to Civic Federation (2021), but just knowing there are too many local governments does not mean that we know which jurisdictions should be bundled together.

It is also not clear that better monitoring is welfare enhancing. Transparency can be bad for voters and can lead to pandering by politicians (Fox 2007; Fox and Van Weelden 2012; Ashworth

\footnotetext{
${ }^{1}$ In Washington State, for example, rolloff can typically exceed 10\% (Marble 2017).
} 
and Shotts 2010; Prat 2005; Wolton 2019). This paper uses a formal model to first see when having one elected official in charge of two policy areas is better than having two officials each in charge of a single area. It then sees how this changes when it is costly for voters to monitor politicians.

To analyze these questions, I take a standard model of political accountability and modify it in two key aspects. First, I look at two policy areas instead of a single policy area. These two policy areas can be overseen by two separate politicians (unbundled) or can be overseen by a single politician (bundled). ${ }^{2}$ I then introduce a monitoring cost for the voter. If the voter does not pay the monitoring cost, she does not know what policy the politician implemented. Crucially, she has to pay this cost for each politician. Therefore she can learn about both policy areas by paying the cost once in the bundled scenario, but must pay the cost for each politician when policies are unbundled.

First, I uncover an equilibrium with bundled policies that is not present with unbundled policies. For some parameter values, a politician in charge in multiple areas will partially pander to the voter. They do this by sometimes implementing the policy the voter thinks is ex-ante optimal and sometimes implementing their preferred policy. Politicians in charge of multiple policy areas have greater flexibility in choosing when to pander while politicians in charge of only a single area either fully pander or fully act sincerely.

Next, I find that the voter is willing to incur a greater cost to monitor a politician in charge of two areas than a politician in charge of one area. The benefit of monitoring when policies are bundles is greater than the benefit of monitoring when policies are unbundled. Note that this is not a cognitive load argument. It is not that monitoring multiple politicians is too costly overall. Instead, it is not worth it to monitor either of the single politicians and therefore the voter may monitor neither when costs are high enough.

When all politicians act sincerely the voter is always better off policy-wise with unbundled policies. The voter's ability to distinguish between good and bad politicians separately for each policy dominates. Because electoral incentives to affect policy choice in this equilibrium, there are only selection effects to consider. Selection is always better with unbundled policies.

\footnotetext{
${ }^{2}$ I also sometimes refer to the politicians themselves as bundled or unbundled.
} 
When all politicians pander, however, the voter is indifferent policy-wise between bundled and unbundled. All politicians choose the exact same first period policy and all are retained. However, since the voter is willing to pay a higher cost to monitor one politician, she may be better off with bundled policies than with unbundled policies.

When politicians are in charge of multiple policy areas, the optimal institution is dependent on the behavior of politicians in charge of single policies and the supply of good politicians. In general, as the supply of high quality politicians decreases, the voter wants to encourage more pandering by politicians. The first period policy effects outweigh the second period selection benefits. Sometimes bundled policy encourages partial pandering when unbundled policy encourages sincere policymaking. In these cases, the partial pandering is an improvement for the voter when politician quality is low. However, bundling also encourages partial pandering in some cases when unbundled politicians would fully pander. In this case, bundling is better when the supply of good politicians is high. There is a tension between better first period behavior and better selection. Selection is more important when the probability of a good politician is high while better first period behavior is more important in the reverse scenario.

Both Ashworth and Bueno de Mesquita (2017) and Landa and Le Bihan (2018) use a career concerns framework where uncertainty is symmetric to study policy bundling. The current manuscript looks at asymmetric uncertainty and is better suited to ideological conflicts across multiple tasks than the issues of effort and competence discussed in the cited papers. Ash, Morelli and Van Weelden (2017) shows how greater transparency can push politicians to spend more time on divisive issues instead of common-value issues.

This model presented here is related, but distinct from the literature on local versus centralized government. In these models (Besley and Coate (2003), for example) local governments have more accurate information about local conditions but the central government can better coordinate to take advantage of spillovers. The hierarchical nature of this question is substantively different from the pure bundling and unbundling question analyzed here.

There is an extensive literature of asymmetric information in accountability models (Canes- 
Wrone, Herron and Shotts 2001; Maskin and Tirole 2004; Fox and Shotts 2009; Morelli and Van Weelden 2013). ${ }^{3}$ In particular, these models focus on detailing when politicians pander. That is, when politicians ignore their own information on best policies to conform to what the voter ex-ante believes are the best policies.

There are only two papers that I am aware of specifically studying pandering and rational inattention. Trombetta (2020) is the closest model to the current manuscript, but only focuses on a single policy area. Hirsch and Devdariani (2021) also only looks at a single policy area and focuses on competence, not ideology.

A few papers have applied a rational inattention framework to other political scenarios. In particular Prato and Wolton $(2016,2018)$ study how rational inattention affects the effectiveness of political communication and electoral competition. Politicians must exert effort to communicate with voters, but voters must exert effort to pay attention to said communication.

While the model is applied here to elections, bundling is also a more general institutional design issue. For example, Bils (2020) analyzes a delegation model and shows when congress is better off delegating authority to multiple or single agencies. Gratton and Morelli (2020) examines divided versus unified political authority to analyze the optimal set of checks and balances.

\section{Model Basics}

This is a two-period model with one representative voter and one or two politicians. There are two policy areas, $i \in\{\alpha, \beta\}$. In each period $t \in\{1,2\}$, there is a separate state of the world $\omega_{i}^{t} \in\{0,1\}$ for each policy area. The politician in charge of policy area $i$ in period $t$ chooses policy $x_{i}^{t} \in\{0,1\}$. In between periods 1 and 2, the voter decides whether to retain the incumbent politician for each area. If she fires the politician, a new one is randomly drawn. Payoffs are realized at the end of period 2 .

When monitoring is costly, I assume the voter can only see the policy if she exerts effort to monitor the politician. In particular, the voter must pay a fixed $\operatorname{cost} c$ to learn about the politician's

\footnotetext{
${ }^{3}$ See for Ashworth (2012) and Duggan and Martinelli (2017) a more comprehensive review.
} 
policy choice.

Types Politicians come in two types, Good or Bad, and there are two policy areas, $\alpha$ and $\beta$. I denote the politician with authority of policy $i$ as $P_{\theta_{i}}$ with $\theta \in\{G, B\}$ and $i \in\{\alpha, \beta\}$. If there are two politicians, their types are $P_{\theta_{\alpha}}$ and $P_{\theta_{\beta}}$. If there is one politician, her type is $P_{\theta_{\alpha}, \theta_{\beta}}$. These types are drawn independently, even when there is one politician. The prior probability of a good type is $\pi_{1}=\pi_{2}=\pi$. The probability of a bad type is $(1-\pi)$.

Utilities Voters want policy to match the state of the world. For each policy area, the voter receives a per period payoff of

$$
U_{V_{i}}^{t}=\left\{\begin{array}{l}
1 \text { if } x_{i}^{t}=\omega_{i}^{t} \\
0 \text { if } x_{i}^{t} \neq \omega_{i}^{t}
\end{array}\right.
$$

The voter also incurs a cost, $c$, if she chooses to monitor policy area

Total utility is the discounted sum of per period utilities:

$$
U_{V_{\alpha}}^{1}+U_{V_{\beta}}^{1}+\delta\left(U_{V_{\alpha}}^{2}+U_{V_{\beta}}^{2}\right)
$$

Good politicians when in office share the policy preferences of the voter and also receive an office rent $R$. If they are not in office, they get a total payoff of 0 . Good politicians also only care about the policy for the policy areas they have authority over; they always receive a payoff of 0 for an area outside their jurisdiction.

$$
U_{P_{G_{i}}}^{t}=I \cdot R+I \cdot D \cdot\left\{\begin{array}{l}
1 \text { if } x_{i}^{t}=\omega_{i}^{t} \\
0 \text { if } x_{i}^{t} \neq \omega_{i}^{t}
\end{array}\right.
$$

where $I=1$ if the politician is in office, 0 otherwise and $D=1$ if the policy is under her jurisdiction, 0 otherwise. Total utility is the discounted sum of per period utilities:

$$
U_{P_{G_{\alpha}}}^{1}+U_{P_{G_{\beta}}}^{1}+\delta\left(U_{P_{G_{\alpha}}}^{2}+U_{P_{G_{\beta}}}^{2}\right)
$$


When in office, bad politicians want policy to be the opposite of the state also receive an office rent $R$. If they are not in office, they get a total payoff of 0 . Bad politicians also only care about the policy for the policy areas they have authority over; they always receive a payoff of 0 for an area outside their jurisdiction.

$$
U_{P_{B_{i}}}^{t}=I \cdot R+I \cdot D \cdot\left\{\begin{array}{l}
1 \text { if } x_{i}^{t}=\left(1-\omega^{t}\right) \\
0 \text { if } x_{i}^{t}=\omega^{t}
\end{array}\right.
$$

where $I=1$ if the politician is in office, 0 otherwise and $D=1$ if the policy is under her jurisdiction, 0 otherwise. Total utility is the discounted sum of per period utilities:

$$
U_{P_{B \alpha}}^{1}+U_{P_{B_{\beta}}}^{1}+\delta\left(U_{P_{B \alpha}}^{2}+U_{P_{\beta}}^{2}\right)
$$

Information Politicians know their own types and the states of the world. Voters only know the priors for both. For the baseline model, I will let the voter observe the policy but not the outcome. In the costly monitoring section, I will let the voter only observe the policy if monitoring is successful. The probability that the state of the world for policy area $i, \omega_{i}=1$ is $q$. Similarly the probability $\omega_{i}=0$ is $(1-q)$. Policy areas are independent. I assume $q \geq \frac{1}{2}$.

Equilibrium Because the voter is uncertain about the politician types, I use Perfect Bayesian Equilibrium in pure strategies (hereafter just "equilibrium") as our solution concept. As a tie-breaking rule, I assume politicians pool when they are indifferent.

\section{Discussion and Assumptions}

I assume that $q \geq \frac{1}{2}$. Therefore the state of the world is more likely to be 1 . I also assume that $\pi q \geq(1-\pi)(1-q)$. When politicians act sincerely and the voter observes $x=1$, the politician is more likely to be a good type. The opposite is true when the voter observes $x=0$.

I also assume that when the voter does not monitor politicians, they are reelected with certainty. This simplifies the analysis, but is not necessary for the results. Behavior and voter welfare 
would be the same for any decision rule that does not condition on policy choice.

While the monitoring cost is similar to a general election cost, they are not exactly the same. The results are qualitatively the same if the voter just chooses randomly, or even relies solely on partisan cues. For example, consider a Presidential election. The election cost is spread over all of the offices on the ballot while the monitoring cost is separate for each office on the ballot. When the voter does not know what the candidates have accomplished and votes randomly, all of the results hold.

Finally, I define a few terms to make the rest of the exposition clearer. A politician panders if they ignore their own information to improve their chances of reelection. A politician acts sincerely if they use their information about the state of the world to choose her preferred policy. I will often use pandering and pooling interchangeably.

\section{Analysis}

To establish a baseline for when bundling is better than unbundling, I first look at the equilibria without monitoring. In the second period, politicians will always implement their preferred policies as the voter can no longer hold them accountable. Therefore the voter's retention decision is driven by her desire to have good types in office in the second period. She will reelect an incumbent if the voter believes the incumbent is more likely than the challenger to be a good type. For the rest of the paper, I focus on first period behavior and suppress the $t$ superscript.

\section{Two Politicians}

Because the the two policy areas and the politicians' types are independent, the voter considers each retention decisions separately. Therefore, I characterize the equilibrium in terms of a single politician in charge of a single area.

Proposition 1. Let policy areas be unbundled and there be automatic monitoring. Then the voter retains all politicians who implement $x=1$ and fires all politicians who implement $x=0$. Each 
politician will pander if $R \geq \frac{1-\delta}{\delta}$ and act sincerely otherwise. ${ }^{4}$

Notice politicians will be willing to pander as they become more patient and the rents to office become greater.

\section{One Politician}

With one politician in charge of two areas, the voter's problem is now more complicated. What should she believe about the politician's type if sees first period policies of $(1,0)$ ? Denote her posteriors about the politician's types as $\hat{\pi}_{1}$ and $\hat{\pi}_{2}$. Reelecting the incumbent has an expected utility of

$$
\hat{\pi}_{1}+\hat{\pi}_{2}
$$

Electing the challenger has an expected utility of

$$
\pi+\pi
$$

Reelecting the incumbent is better than electing the challenger if

$$
\frac{\hat{\pi}_{1}+\hat{\pi}_{2}}{2} \geq \pi
$$

This gives the politician more flexibility in the first period. I will be able to construct an equilibrium where the politician can choose $(1,0)$ and get reelected. If the likelihood of a good type is low enough, the voter may better off settling for a semi-good type than gambling on getting a total good type in the next period.

Proposition 2. Let policy areas be bundled and there be automatic monitoring. Then if $\pi \geq \frac{1}{2}$ or if $\pi<\frac{1}{2}$ and $R \geq \frac{(1-2 \delta)}{\delta}$, the voter retains all politicians who implement $\left(x_{1}, x_{2}\right)=(1,1)$ and fires all politicians who implement $\left(x_{1}, x_{2}\right) \neq(1,1)$. If $\pi<\frac{1}{2}$ and $R<\frac{(1-2 \delta)}{\delta}$ the voter retains all politicians who implement $\left(x_{1}, x_{2}\right) \neq(0,0)$ and fires all politicians who implement $\left(x_{1}, x_{2}\right)=(0,0)$.

\footnotetext{
${ }^{4}$ All proofs in the appendix.
} 
The politician acts sincerely if $R<\frac{(1-2 \delta)}{\delta}$, partially panders if $R \in\left[\frac{(1-2 \delta)}{\delta}, \frac{2(1-\delta)}{\delta}\right)$ and fully panders if $R \geq \frac{2(1-\delta)}{\delta}$.

Note that the distribution of good and bad types doesn't play a role in determining the equilibrium with two politicians, but does with one. The voter is willing to retain a politician who implements $(1,0)$ or $(0,1)$ in a sincere equilibrium if the probability of a good politician is low enough.

The politician's policy utility can now be 0,1 , or 2 instead of just 1 or 0 in the unbundled case. In the partial pandering equilibrium, he is willing to give up one policy area today to be reelected, but not both. In the full pandering equilibrium, office rents are large enough that the politician is willing to give up on both policy areas today in order to be reelected.

\section{Comparisons}

I can now compare the voter's welfare under bundled and bundled policies. Denote the equilibrium cutoffs as

$$
\begin{aligned}
\tilde{R} & :=\frac{(1-\delta)}{\delta} \\
\underline{R} & :=\frac{(1-2 \delta)}{\delta} \\
\bar{R} & :=\frac{2(1-\delta)}{\delta}
\end{aligned}
$$

The full pooling cutoff is higher in the one politician case than the than the pooling cutoff in the two politician case. The single politician has a higher possible policy utility, and therefore needs to receive higher rents in order to fully pool. However, the partial pooling cutoff is lower than the one politician full pooling cutoff. Partially pooling allows the politician to stay in office while not completely giving up on policy in a way that politicians in charge of only one policy area cannot match. Tables 1 and 2 summarize the set of equilibria and their associated cutoffs.

Note that for a given value of $R$, there may be heterogeneity in how unbundled vs unbundled politicians behave. In particular, whenever bundled politicians partially pander, unbundled politi- 


\begin{tabular}{|l||c|c|c|}
\hline & $R<\frac{(1-2 \delta)}{\delta}$ & $R \in\left[\frac{(1-2 \delta)}{\delta}, \frac{2(1-\delta)}{\delta}\right)$ & $R \geq \frac{2(1-\delta)}{\delta}$ \\
\hline \hline$\pi \geq \frac{1}{2}$ & Sincere, semi-good not retained & Partial Pandering & Pandering \\
\hline$\pi<\frac{1}{2}$ & Sincere, semi-good retained & Partial Pandering & Pandering \\
\hline
\end{tabular}

Table 1: Cutoffs for Bundled Politicians

\begin{tabular}{|l||c|c|}
\hline & $R<\frac{(1-\delta)}{\delta}$ & $R \geq \frac{(1-\delta)}{\delta}$ \\
\hline \hline$\pi \geq \frac{1}{2}$ & Sincere & Pandering \\
\hline$\pi<\frac{1}{2}$ & Sincere & Pandering \\
\hline
\end{tabular}

Table 2: Cutoffs for Unbundled Politicians

cians either act sincerely or fully pander. In this case, whether one or two politicians is better for the voter depends on the unbundled politicians behavior and the distribution of good and bad politician types.

Proposition 3. Let $R<\frac{(1-2 \delta)}{\delta}$. Then unbundled policy areas are always better for the voter. Let $R \geq \frac{2(1-\delta)}{\delta}$. Then the voter is indifferent between bundled and unbundled policies. Let $R \in$ $\left[\frac{(1-2 \delta)}{\delta}, \frac{(1-\delta)}{\delta}\right)$. Then bundled policies are better for the voter if $\pi \leq \pi^{\prime}$. Let $R \in\left[\frac{(1-\delta)}{\delta}, \frac{2(1-\delta)}{\delta}\right)$. Then bundled policies are better for the voter if $\pi \geq \pi^{\prime \prime} .5$

In general, the voter is better off with sincere policymaking when the supply of good candidates is high. When there is a high chance of a good politician, two things make sincere policymaking optimal. One, there is a high probability of a good politician in the first period. Therefore the voter would like the good politician to use her information and match policy to the state of the world. Two, if the voter does fire the politician, there is a high probability that the next period's politician will be a good type. Therefore firing the politician does not carry much risk.

When the supply of good politicians is low, however, the voter is better off when politicians pander. The first period politician is likely to be a bad type, and there voter is ex-ante better off if she knows the politician will choose $x=1$ regardless of the state of the world. Identifying bad politicians is not as important; if a bad politician was fired, it is likely another bad politician would replace him. These general insights translate to the comparison of bundled vs unbundled policy

\footnotetext{
${ }^{5} \pi^{\prime}$ and $\pi^{\prime \prime}$ are formally defined in the appendix.
} 
areas.

When politicians act sincerely, unbundled policies are unambiguously better for voter. The voter can be parsimonious in using her information to select good types. There is no benefit to only retaining politicians that implement $(1,1)$ or $(1,0)$ over being able to base the retention decision solely on $x_{1}=1$ and $x_{2}=1$.

As $R$ increases, however, bundled politicians start to partially pandering while unbundled politicians keep acting sincerely. This partial pandering limits the upside of good and semi-good types, but also limits the downside of bad and semi-good types. As $\pi$ decreases, partial pandering becomes better for the voter. If $\pi$ is high, however, then the voter would prefer policies to be unbundled and politicians to act sincerely.

At $R=\frac{(1-\delta)}{\delta}$, this relationship reverses. Now unbundled politicians fully pander while bundled politicians still only partially pander. In the $R \in\left[\frac{(1-\delta)}{\delta}, \frac{2(1-\delta)}{\delta}\right)$ parameter range, there is more sincere policymaking with bundled policies than with unbundled policies. Therefore, bundled politicians are now optimal when the supply of good politicians is high and unbundled politicians are optimal when the supply of good politicians is low. Figure 1 gives a visual example of the optimal equilibria.

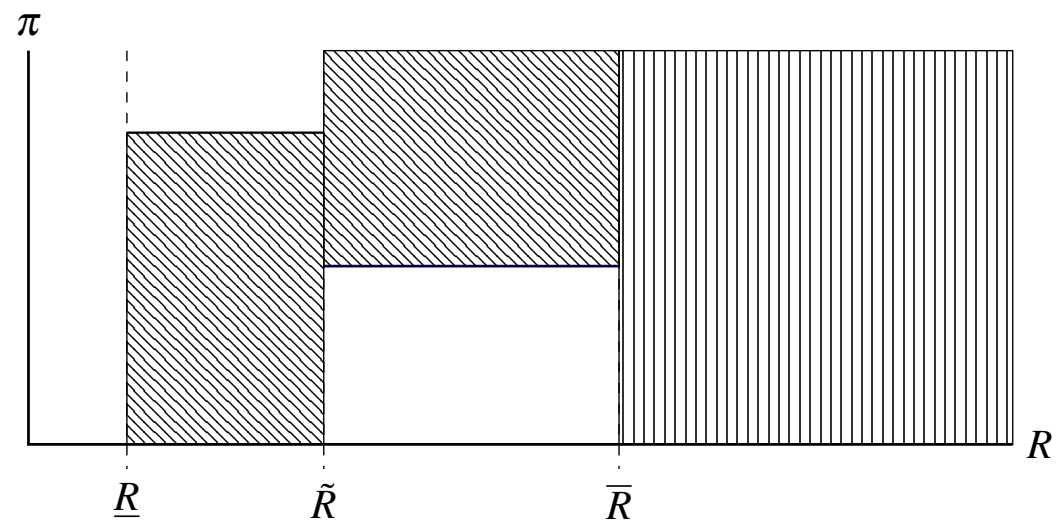

Figure 1: Voter Optimal Equilibria under automatic monitoring for $q=.8$ and $\delta=.4$. No filling for when two politicians are optimal. Diagonal lines for when one politician is optimal. Vertical lines for when the voter is indifferent. 


\section{Monitoring}

Given that I now know when one politician is better than two, does costly monitoring change the situation? Note that politicians will simply choose their preferred first period policies when voters do not monitor. If they won't be fired (since the voter won't observe the policy), then why pander to the voter? Also, note that with a fixed $\operatorname{cost} c$ the voter will either monitor both politicians (under the 2 politician framework) or neither since there is no budget constraint and the politician types are independent.

The voter's utility from not monitoring is the same regardless of the numbers of politicians:

$$
2 \pi(1+\delta)
$$

The voter's non-monitoring utility is strictly increasing in $\pi$. In turn, the amount the voter is will to pay is also decreasing in $\pi$. This is shown most clearly in the pandering equilibria. The maximum the voter is willing to pay to monitor is $q-\pi$ in the unbundled case and $2(q-\pi)$. In fact, even when monitoring is free, the voter may choose to not monitor. This is precisely because when the probability of a good politician is high enough, she does not want to encourage pandering.

Proposition 4. Assume $\pi \leq q \cdot{ }^{6}$ Then the voter is always willing to pay more monitor bundled politicians than unbundled politicians.

It is more valuable to monitor politicians in charge of multiple areas. Again, this is most clear in the pandering scenario where the voter is willing pay twice as much to monitor a politician in charge of two policies. Note that this is not the total cost of monitoring two politicians being too high; instead it is more valuable for a voter to monitor a politician in charge of multiple policies. This is not an issue that would be solved with concurrent elections; an electoral cost may be mitigated, but the monitoring cost would still be present.

Note that the unmonitored utility is the same for both bundled and unbundled policy areas.

\footnotetext{
${ }^{6} \pi \leq q$ is a sufficient condition.
} 
Therefore, if the voter is willing to monitor a politician with a bundled policy portfolio, but not a politician in charge of a single area, her utility must be greater under bundled politicians. Bundling policies with $c \in\left[\bar{c}_{u}, \bar{c}_{b}\right]^{7}$ is always welfare enhancing.

The statement is even stronger when politicians pander. Because the pooling utility is the same for bundled and unbundled policies, the voter is always (weakly) better off with bundled policies. Unless the cost of monitoring unbundled politicians is less than half of the cost of monitoring bundled politicians, it is better for the voter to monitor one pandering politician than two pandering politicians. Figures 2 and 3 shows how the voter's utility changes as the monitoring costs changes for both pandering and sincere equilibria.

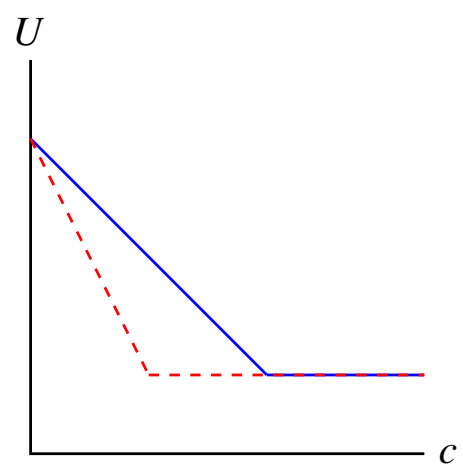

Figure 2: Voter's utility by cost for pandering equilibria. Solid line for bundled, dashed line for unbundled.

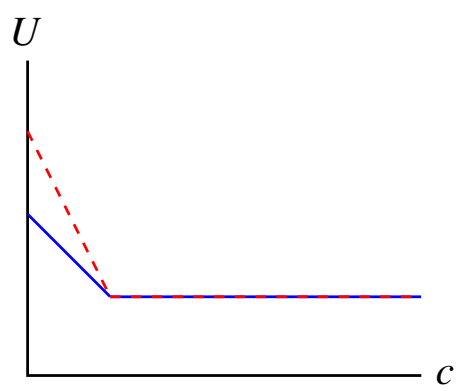

Figure 3: Voter's utility by cost for sincere equilibria. Solid line for bundled, dashed line for unbundled.

\footnotetext{
${ }^{7} \bar{c}_{u}$ is the maximum monitoring cost for unbundled, $\bar{c}_{b}$ is the maximum monitoring cost for bundled.
} 


\section{Conclusion}

In this paper, I have shown how politicians behave when they have private information about their type. In particular, I have shown how politicians in charge of multiple policy areas may only partially pander to voters in a way politicians in charge of only a single area cannot do. This creates space for bundled policy areas to sometimes, but not always, be better than unbundled policy areas for voters. I then show that voters are willing to put in more effort to monitor bundled policy areas than unbundled areas.

In light of these results, it is worth returning back to some of the examples from the introduction. One of the worries from Anzia (2011) and Berry and Gersen (2010) is that non-concurrent elections will be more easily captured by special interests. A way to interpret that statement is that moving from bundled policy areas to unbundled policies will let politicians more freely implement policies against the voters' interests. By keeping policy areas bundled, voters may be willing to mon-

itor politicians and induce pandering. If the supply of high quality candidates is low, this pandering is actually welfare enhancing. Bundling can encourage pandering by increasing the willingness to monitor and at times this pandering is a good thing.

\section{References}

Anzia, Sarah F. 2011. "Election timing and the electoral influence of interest groups." The Journal of Politics 73(2):412-427.

Anzia, Sarah F. 2013. Timing and turnout: How off-cycle elections favor organized groups. University of Chicago Press.

Ash, Elliott, Massimo Morelli and Richard Van Weelden. 2017. "Elections and divisiveness: Theory and evidence." The Journal of Politics 79(4):1268-1285.

Ashworth, Scott. 2012. "Electoral accountability: Recent theoretical and empirical work." Annual Review of Political Science 15:183-201. 
Ashworth, Scott and Ethan Bueno de Mesquita. 2017. "Unified versus divided political authority." The Journal of Politics 79(4):1372-1385.

Ashworth, Scott and Kenneth W Shotts. 2010. "Does informative media commentary reduce politicians' incentives to pander?" Journal of Public Economics 94(11-12):838-847.

Berry, Christopher R. 2009. Imperfect Union: Representation and Taxation in Multilevel Governments. Political Economy of Institutions and Decisions Cambridge University Press.

Berry, Christopher R and Jacob E Gersen. 2010. "The timing of elections.” U. Chi. L. Rev. 77:37.

Besley, Timothy and Stephen Coate. 2003. "Centralized versus decentralized provision of local public goods: a political economy approach.” Journal of public economics 87(12):2611-2637.

Bils, Peter. 2020. "Policymaking with Multiple Agencies.” American Journal of Political Science 64(3):634-648.

Canes-Wrone, Brandice, Michael C Herron and Kenneth W Shotts. 2001. "Leadership and pandering: A theory of executive policymaking." American Journal of Political Science pp. 532-550.

Civic Federation, The. 2021. "An Inventory of Local Governments in Illinois.”. URL: https://www.civicfed.org/inventory

Duggan, John and César Martinelli. 2017. "The political economy of dynamic elections: Accountability, commitment, and responsiveness." Journal of Economic Literature 55(3):916-84.

Fox, Justin. 2007. “Government transparency and policymaking.” Public choice 131(1-2):23-44.

Fox, Justin and Kenneth W Shotts. 2009. "Delegates or trustees? A theory of political accountability." The Journal of Politics 71(4):1225-1237.

Fox, Justin and Richard Van Weelden. 2012. "Costly transparency." Journal of Public Economics 96(1-2):142-150. 
Gratton, Gabriele and Massimo Morelli. 2020. “Optimal checks and balances under policy uncertainty." CEPR Discussion Paper No. DP14745 .

Landa, Dimitri and Patrick Le Bihan. 2018. "Does Unbundling Policy Authority Improve Accountability?" The Journal of Politics 80(3):933-947.

Marble, William. 2017. "Mail Voting Reduces Ballot Roll-Off: Evidence from Washington State.”. URL: https://williammarble. co/docs/rolloff_vbm. pdf

Maskin, Eric and Jean Tirole. 2004. "The politician and the judge: Accountability in government." American Economic Review 94(4):1034-1054.

Morelli, Massimo and Richard Van Weelden. 2013. "Ideology and information in policymaking." Journal of Theoretical Politics 25(3):412-439.

Prat, Andrea. 2005. "The wrong kind of transparency.” American economic review 95(3):862-877.

Prato, Carlo and Stephane Wolton. 2016. “The voters' curses: why we need Goldilocks voters." American Journal of Political Science 60(3):726-737.

Prato, Carlo and Stephane Wolton. 2018. "Rational ignorance, populism, and reform." European Journal of Political Economy 55:119-135.

Trombetta, Federico. 2020. "When the light shines too much: Rational inattention and pandering." Journal of Public Economic Theory 22(1):98-145.

Wolton, Stephane. 2019. “Are biased media bad for democracy?” American Journal of Political Science 63(3):548-562. 


\section{Appendices}

I first establish the equilibria for one and two politicians assuming monitoring is automatic before moving on to equilibria with monitoring.

\section{A Equilibria with Automatic Monitoring}

\section{A.1 Two Politicians}

Lemma 1. Let policy areas be unbundled and automatic monitoring. Then each politician will pool if $R \geq \frac{1-\delta}{\delta}$ and act sincerely otherwise.

Proof. Assume that the voter retains all politicians who implement $x=1$ and fires all politicians who implement $x=0$. I first look at pooling on $x=1$.

In the pooling equilibrium, I check a deviation to $x=0$ when $x=1$ is optimal. The math is the same for both types:

$$
0+\delta(1+R)
$$

Expected utility of $x=1$ :

Pooling is sustainable if

$$
\begin{aligned}
\delta(1+R) & \geq 1 \\
R & \geq \frac{1-\delta}{\delta}
\end{aligned}
$$

In the sincere equilibrium, the bad type is reelected when $\omega^{1}=0$ and the good type is only reelected when $\omega^{1}=1$. Assume that $x=0$ is optimal and I check a deviation to $x=1$. Expected utility of $x=1$ in the first period:

$$
0+\delta(1+R)
$$


Expected utility of $x=0$ :

Sincere is sustainable if

$$
\begin{aligned}
\delta(1+R) & \leq 1 \\
R & \leq \frac{1-\delta}{\delta}
\end{aligned}
$$

The equilibria are mutually exclusive except right at $\frac{1-\delta}{\delta}$.

Denote $\frac{1-\delta}{\delta}$ as $\tilde{R}$.

Proposition 5. Let policy areas be unbundled and automatic monitoring. Then the voter retains all politicians who implement $x=1$ and fires all politicians who implement $x=0$. Each politician will pool if $R \geq \frac{1-\delta}{\delta}$ and act sincerely otherwise.

Proof. In the pandering equilibrium, fix off-path beliefs such if the voter observes 0 , she believes the politician to be bad. Note that I assume that $\pi q \geq(1-\pi)(1-q)$ and assume the voter retains politicians when indifferent between firing and retaining. Therefore voters believe the politician is more likely to be a good type when they observe $x=1$, when politicians act sincerely and her posterior matches the prior when politicians pool. Because the voter only wants to retain politicians she believes are more likely to be good times, she only retains politicians who choose $x=1$. This fact combined with the above lemma completes the proof.

\section{A.2 One Politician}

Lemma 2. When policy areas are bundled, the politician will act sincerely when $R<\frac{(1-2 \delta)}{\delta}$, partially pool when $R \in\left[\frac{(1-2 \delta)}{\delta}, \frac{2(1-\delta)}{\delta}\right)$, and fully pool when $R \geq \frac{2(1-\delta)}{\delta}$.

Proof. Full Pooling For the full pooling equilibrium I consider pooling on $(1,1)$ when the voter fires any politician who chooses any other policy. I check the deviation from $(1,1)$ to $(0,0)$ when 
$(0,0)$ is optimal in the first period. This is when it is mostly costly for the politician to pool instead of acting sincerely.

Expected utility from $(1,1)$ when $(0,0)$ is optimal:

$$
0+\delta(2+R)
$$

Expected utility from $(0,0)$ :

Pooling is optimal if

$$
R \geq \frac{2(1-\delta)}{\delta}
$$

\section{Sincere Policy-making}

If the probability of a good type is low enough, sincere policymaking with reelection for (1, 0) can be sustained by the voter. Now I check when it can be sustained from the politician's side both with reelection for $(1,0)$ and with no reelection for $(1,0)$. First I look at no reelection for $(1,0)$. Again, the math is the same as in the pooling case:

Expected utility from $(1,1)$ when $(0,0)$ is optimal:

$$
0+\delta(2+R)
$$

Expected utility from $(0,0)$ :

Sincere is better than pooling if

$$
R \leq \frac{2(1-\delta)}{\delta}
$$

I also need to check the utility difference for a single policy deviation. Let $(1,0)$ be the 
optimal policy ( $(0,1$ is similar $))$ Expected utility from $(1,1)$

$$
1+\delta(2+R)
$$

Expected utility from $(1,0)$ :

Sincere is optimal if

$$
\begin{aligned}
& 2>1+\delta(2+R) \\
& 1>\delta(2+R) \\
& R<\frac{1-2 \delta}{\delta}
\end{aligned}
$$

Therefore a sincere equilibrium is only sustainable if $R<\frac{1-2 \delta}{\delta}$

\section{Partial Pooling}

For partial pooling, I need the politician to be willing to pool on $(1,1)$ if their optimal policy is $(1,1),(1,0)$, or $(0,1)$ but not if the optimal policy is $(0,0)$. I need to check that a deviation from $(1,1)$ to $(1,0)$ is not optimal. Partial Pooling is optimal if

$$
\begin{aligned}
& 2 \leq 1+\delta(2+R) \\
& 1 \leq \delta(2+R) \\
& R \geq \frac{1-2 \delta}{\delta}
\end{aligned}
$$

However, I do need that the politician is not willing to pool when the optimal policy is $(0,0)$. From above, I know that that cutoff is $R \leq \frac{2(1-\delta)}{\delta}$.

Therefore partial pooling is sustainable if $R \in\left[\frac{1-2 \delta}{\delta}, \frac{2(1-\delta)}{\delta}\right)$.

Lemma 3. Let $\pi \geq \frac{1}{2}$. Then, in a sincere equilibrium, the voter fires politicians who implement (1, 
$0)$. Let $\pi<\frac{1}{2}$. Then, in a sincere equilibrium, the voter retains politicians who implement $(1,0)$.

Proof. There are two possible sincere policy-making equilibria. One where politicians are fired when they choose $(1,0)$ or $(0,1)$ and one where they are retained. Note that they are always fired when choosing $(0,0)$. Assuming the sincere equilibrium exists, when will the voter fire or retain? To retain when she sees $(1,0)$, I need

$$
\frac{\hat{\pi}_{1}+\hat{\pi}_{2}}{2} \geq \pi
$$

Because the types are independent, I can solve for each posterior separately:

$$
\begin{aligned}
\operatorname{Pr}(G \mid 1) & =\frac{\operatorname{Pr}(1 \mid G) \cdot \operatorname{Pr}(G)}{\operatorname{Pr}(1)} \\
& =\frac{\operatorname{Pr}(1 \mid G) \cdot \operatorname{Pr}(G)}{\operatorname{Pr}(1 \mid G) \cdot \operatorname{Pr}(G)+\operatorname{Pr}(1 \mid B) \cdot \operatorname{Pr}(B)} \\
& =\frac{\pi \cdot q}{\pi \cdot q+(1-\pi) \cdot(1-q)} \\
\operatorname{Pr}(G \mid 0) & =\frac{\operatorname{Pr}(0 \mid G) \cdot \operatorname{Pr}(G)}{\operatorname{Pr}(0)} \\
& =\frac{\operatorname{Pr}(0 \mid G) \cdot \operatorname{Pr}(G)}{\operatorname{Pr}(0 \mid G) \cdot \operatorname{Pr}(G)+\operatorname{Pr}(0 \mid B) \cdot \operatorname{Pr}(B)} \\
& =\frac{(1-q) \pi}{(1-q) \pi+q(1-\pi)}
\end{aligned}
$$

Retain if

$$
\begin{array}{r}
\frac{\pi \cdot q}{\pi \cdot q+(1-\pi) \cdot(1-q)}+\frac{(1-q) \pi}{(1-q) \pi+q(1-\pi)} \geq 2 \pi \\
\pi \leq \frac{1}{2}
\end{array}
$$

Lemma 4. In a partial pooling equilibrium, the voter only retains politicians who implement $(1,1)$. 
Proof. What does partial pooling look like? First, I need politicians to pool on $(1,1)$ only some of the time. For example, I need a good type to choose $(1,1)$ for states of the world $(1,1),(1,0),(0,1)$ but not $(0,0)$. This requires $R \in\left[\frac{(1-2 \delta)}{\delta}, \frac{2(1-\delta)}{\delta}\right)$.

If the voter observes $(1,1)$, will she reelect? First I calculate the posteriors for $\pi_{1}$ and $\pi_{2}$. Note that $\hat{\pi}_{1}$ will equal $\hat{\pi}_{2}$ so I only show the calculation once.

$$
\begin{aligned}
\operatorname{Pr}(G \mid 1) & =\frac{\operatorname{Pr}(1 \mid G) \cdot \operatorname{Pr}(G)}{\operatorname{Pr}(1)} \\
& =\frac{\operatorname{Pr}(1 \mid G) \cdot \operatorname{Pr}(G)}{\operatorname{Pr}(1 \mid G) \cdot \operatorname{Pr}(G)+\operatorname{Pr}(1 \mid B) \cdot \operatorname{Pr}(B)} \\
& =\frac{\left(q^{2}+2 q(1-q)\right) \pi^{2}+\left(q^{2}+q(1-q)+(1-q)^{2}\right) \pi(1-\pi)}{\left(q^{2}+2 q(1-q)\right) \pi^{2}+\left(q^{2}+q(1-q)+(1-q)^{2}\right) \pi(1-\pi)+\left(2 q(1-q)+(1-q)^{2}\right)(1-\pi)^{2}+\left(q^{2}+q\right.} \\
& =\frac{\pi\left(q-q^{2}-1\right)+\pi^{2}\left(1-3 q+2 q^{2}\right)}{-1+2 \pi\left(q-2 q^{2}\right)+\pi^{2}(1-2 q)^{2}+q^{2}}
\end{aligned}
$$

For the voter to retain, I need

$$
\begin{array}{r}
\frac{\hat{\pi}_{1}+\hat{\pi}_{2}}{2} \geq \pi \\
\frac{\frac{\pi\left(q-q^{2}-1\right)+\pi^{2}\left(1-3 q+2 q^{2}\right)}{-1+2 \pi\left(q-2 q^{2}\right)+\pi^{2}(1-2 q)^{2}+q^{2}}+\frac{\pi\left(q-q^{2}-1\right)+\pi^{2}\left(1-3 q+2 q^{2}\right)}{-1+2 \pi\left(q-2 q^{2}\right)+\pi^{2}(1-2 q)^{2}+q^{2}}}{2} \geq \pi \\
\frac{\pi\left(q-q^{2}-1\right)+\pi^{2}\left(1-3 q+2 q^{2}\right)}{-1+2 \pi\left(q-2 q^{2}\right)+\pi^{2}(1-2 q)^{2}+q^{2}}
\end{array}
$$

which is true as long as $q \geq \frac{1}{2}$. Note that this also means the voter will fire if she sees $(0,0)$ as long as $q \geq \frac{1}{2}$. Since I assume that, it is always true and partial pooling can be sustained.

Now consider an equilibrium where the voter retains when all politicians implement $(1,1),(1,0)$, or $(0,1)$ but NOT $(0,0)$. Is retaining at $(1,0)$ optimal?

Who chooses $(1,0)$ ? A G,G type when the state is $(1,0)$, a G, B type when the state is $(1,1)$, a B, G type when the state is $(0,0)$ and a B, B type when the state is $(0,1)$. However, they may also choose $(1,0)$ when their preference is to choose $(0,0)$. A G,G type when the state is $(0,0)$, a G, B type when the state is $(0,1)$, a $B, G$ type when the state is $(1,0)$ and a B, B type when the state is 
$(1,1)$.

To retain when seeing $(1,0)$, I need $\frac{\hat{\pi}_{1}+\hat{\pi}_{2}}{2} \geq \pi$.

$$
\begin{aligned}
\operatorname{Pr}\left(G_{1} \mid 1\right) & =\frac{\operatorname{Pr}(1 \mid G) \cdot \operatorname{Pr}(G)}{\operatorname{Pr}(1)} \\
& =\frac{\operatorname{Pr}(1 \mid G) \cdot \operatorname{Pr}(G)}{\operatorname{Pr}(1 \mid G) \cdot \operatorname{Pr}(G)+\operatorname{Pr}(1 \mid B) \cdot \operatorname{Pr}(B)} \\
& =\frac{\pi^{2}\left(q(1-q)+(1-q)^{2}\right)+\pi(1-\pi) \cdot 2 q(1-q)}{\pi^{2}\left(q(1-q)+(1-q)^{2}\right)+\pi(1-\pi) \cdot 2 q(1-q)+\pi(1-\pi)\left((1-q)^{2}+q(1-q)\right)+(1-\pi)^{2}(q(1-q)-} \\
& =\frac{\pi(q-1)(\pi(2 q-1)-2 q)}{q+\pi^{2} 2 q(2 q-1)-\pi\left(2 q^{2}+q-1\right)}
\end{aligned}
$$

$$
\begin{aligned}
\operatorname{Pr}\left(G_{2} \mid 0\right) & =\frac{\operatorname{Pr}(0 \mid G) \cdot \operatorname{Pr}(G)}{\operatorname{Pr}(0)} \\
& =\frac{\operatorname{Pr}(0 \mid G) \cdot \operatorname{Pr}(G)}{\operatorname{Pr}(0 \mid G) \cdot \operatorname{Pr}(G)+\operatorname{Pr}(0 \mid B) \cdot \operatorname{Pr}(B)} \\
& =\frac{\pi^{2}\left(q(1-q)+(1-q)^{2}\right)+\pi(1-\pi) \cdot\left((1-q)^{2}+q(1-q)\right)}{\pi^{2}\left(q(1-q)+(1-q)^{2}\right)+\pi(1-\pi) \cdot\left((1-q)^{2}+q(1-q)\right)+\pi(1-\pi) 2 q(1-q)+(1-\pi)^{2}(q(1-q)-} \\
& =\frac{\pi(1-q)}{q+\pi^{2} 2 q(2 q-1)-\pi\left(2 q^{2}+q-1\right)}
\end{aligned}
$$$$
\frac{\pi(q-1)(\pi(2 q-1)-2 q)}{q+\pi^{2} 2 q(2 q-1)-\pi\left(2 q^{2}+q-1\right)}+\frac{\pi(1-q)}{q+\pi^{2} 2 q(2 q-1)-\pi\left(2 q^{2}+q-1\right)} \geq 2 \pi
$$

This is never true (from Mathematica).

Proposition 6. Let policy areas be bundled and there be automatic monitoring. Then if $\pi \geq \frac{1}{2}$ or if $\pi<\frac{1}{2}$ and $R \geq \frac{(1-2 \delta)}{\delta}$, the voter retains all politicians who implement $\left(x_{1}^{1}, x_{2}^{1}\right)=(1,1)$ and fires all politicians who implement $\left(x_{1}^{1}, x_{2}^{1}\right) \neq(1,1)$. If $\pi<\frac{1}{2}$ and $R<\frac{(1-2 \delta)}{\delta}$ the voter retains all politicians who implement $\left(x_{1}^{1}, x_{2}^{1}\right) \neq(0,0)$ and fires all politicians who implement $\left(x_{1}^{1}, x_{2}^{1}\right)=(0,0)$.

The politician acts sincerely if $R<\frac{(1-2 \delta)}{\delta}$, partially panders if $R \in\left[\frac{(1-2 \delta)}{\delta}, \frac{2(1-\delta)}{\delta}\right)$ and fully 
panders if $R \geq \frac{2(1-\delta)}{\delta}$.

Proof. Define off-path beliefs such that voter believes a politician who chooses $(1,0)$ or $(0,1)$ in the partial pandering equilibrium and $(0,0),(1,0)$ or $(0,1)$ in the full pandering equilibrium is a bad type. Then the postulated equilibrium is true from the above lemmas.

\section{A.3 Welfare Comparisons}

To determine welfare effects, first I need to calculate the voter's expected utilities. First, the no monitoring utility (which is the same for both bundled and unbundled politicians):

$$
E U(N M)=(1+\delta)\left(2 \pi^{2}+2(1-\pi) \pi\right)=2 \pi(1+\delta)
$$

Two politicians First, for the two politician case. First, let $R \geq \tilde{R}$ :

$$
\begin{aligned}
E U(R \geq \tilde{R}) & =2 q^{2}+2 q(1-q)+(1-q)^{2} 0+\delta\left[2 \pi^{2}+2 \pi(1-\pi)+(1-\pi)^{2} 0\right] \\
& =2 q^{2}+2 q(1-q)+\delta\left[2 \pi^{2}+2 \pi(1-\pi)\right] \\
& =2(q+\delta \pi)
\end{aligned}
$$

Next $R<\tilde{R}$

$$
\begin{aligned}
E U(R<\tilde{R}) & =\pi^{2}\left(\delta\left((2 \pi)(1-q)^{2}+2(\pi+1) q(1-q)+2 q^{2}\right)+2\right) \\
& +(1-\pi)^{2}\left(\delta\left((\pi+\pi) q^{2}+2(\pi+0) q(1-q)+0(1-q)^{2}\right)+0\right) \\
& +2 \pi(1-\pi)\left(\delta\left((\pi+1) q^{2}+\pi(1-q)^{2}+(2 \pi) q(1-q)+q(1-q)\right)+1\right)
\end{aligned}
$$

Simplifying

$$
E U(R<\tilde{R})=2 \pi(\pi(\delta-2 \delta q)+2 \delta q+1)
$$


One politician Pooling:

$$
\begin{aligned}
E U(R \geq \bar{R}) & =2 q^{2}+2 q(1-q)+(1-q)^{2} 0+\delta\left[2 \pi^{2}+2 \pi(1-\pi)+(1-\pi)^{2} 0\right] \\
& =2 q^{2}+2 q(1-q)+\delta\left[2 \pi^{2}+2 \pi(1-\pi)\right] \\
& =2(q+\delta \pi)
\end{aligned}
$$

\section{Sincere, high $\pi$}

$$
\begin{aligned}
E U\left(R<\underline{R} \mid \pi \geq \frac{1}{2}\right) & =\pi^{2}\left(\delta\left(\left(2 \pi^{2}+2(1-\pi) \pi\right)\left(1-q^{2}\right)+2 q^{2}\right)+2\right) \\
& +(1-\pi)^{2}\left(\delta\left(\left(2 \pi^{2}+2(1-\pi) \pi\right)\left(1-(1-q)^{2}\right)\right)+0\right) \\
& +2 \pi(1-\pi)\left(\delta\left(\left(2 \pi^{2}+2(1-\pi) \pi\right)(1-q(1-q))+(1-q) q\right)+1\right)
\end{aligned}
$$

Simplifying

$$
E U\left(R<\underline{R} \mid \pi \geq \frac{1}{2}\right)=2 \pi\left(-\delta \pi^{2}(1-2 q)^{2}+\delta \pi\left(6 q^{2}-7 q+2\right)-2 \delta q^{2}+3 \delta q+1\right)
$$

\section{Sincere, low $\pi$}

$$
\begin{aligned}
E U\left(R<\underline{R} \mid \pi<\frac{1}{2}\right) & =(1-\pi)^{2}\left(\delta\left(\left(2 \pi^{2}+2(1-\pi) \pi\right) q^{2}\right)+0\right) \\
& +2 \pi(1-\pi)\left(\delta\left(\left(2 \pi^{2}+2(1-\pi) \pi\right)(1-q) q+(1-q(1-q))\right)+1\right) \\
& +\pi^{2}\left(\delta\left(\left(2 \pi^{2}+2(1-\pi) \pi\right)(1-q)^{2}+2\left(1-(1-q)^{2}\right)\right)+2\right)
\end{aligned}
$$


Simplifying

$E U\left(R<\underline{R} \mid \pi<\frac{1}{2}\right)=2\left(\delta \pi\left(\pi^{2}(1-2 q)^{2}+\pi\left(-6 q^{2}+5 q-1\right)+2 q^{2}-q+1\right)+\pi\right)$

\section{Partial pooling}

$$
\begin{aligned}
E U(R \in[\underline{R}, \bar{R}]) & =(1-\pi)^{2}\left(\delta\left(\left(2 \pi^{2}+2(1-\pi) \pi\right) q^{2}+0(1-q)^{2}+02 q(1-q)\right)+0 q^{2}+0(1-q)^{2}+2 q(1-q)\right) \\
& +2 \pi(1-\pi)\left(\delta\left(\left(2 \pi^{2}+2(1-\pi) \pi\right)(1-q) q+2(1-q(1-q))\right)+2 q^{2}+0(1-q)^{2}+2 q(1-q)\right) \\
& +\pi^{2}\left(\delta\left(\left(2 \pi^{2}+2(1-\pi) \pi\right)(1-q)^{2}+2 q^{2}+22 q(1-q)\right)+2 q^{2}+2(1-q)^{2}+2 q(1-q)\right)
\end{aligned}
$$

Simplifying

$$
\begin{aligned}
E U(R \in[\underline{R}, \bar{R}]) & =2\left(\pi^{2}\left(-2 \delta-7 \delta q^{2}+(6 \delta-2) q+1\right)\right. \\
& \left.+\delta \pi^{3}(1-2 q)^{2}+\pi\left(2 \delta+(3 \delta+2) q^{2}-2 \delta q\right)-(q-1) q\right)
\end{aligned}
$$

Lemma 5. Under automatic monitoring, the sincere equilibrium with unbundled policies is always better for the voter than the sincere equilibrium with bundled policies.

Proof. I simply compare the expected utilities. First, for high $\pi$ I need

$$
2 \pi(\pi(\delta-2 \delta q)+2 \delta q+1) \geq 2 \pi\left(-\delta \pi^{2}(1-2 q)^{2}+\delta \pi\left(6 q^{2}-7 q+2\right)-2 \delta q^{2}+3 \delta q+1\right)
$$

which is always true. Second, for low $\pi$ I need

$$
2 \pi(\pi(\delta-2 \delta q)+2 \delta q+1) \geq 2\left(\delta \pi\left(\pi^{2}(1-2 q)^{2}+\pi\left(-6 q^{2}+5 q-1\right)+2 q^{2}-q+1\right)+\pi\right)
$$


which again is always true.

Lemma 6. Let there be automatic monitoring and let $R$ be such that unbundled politicians act sincerely and bundled politicians partially pool. Then a bundled politician is better than unbundled politicians for the voter if

$$
\begin{aligned}
\pi & \leq \operatorname{Root}\left[\# I^{3}\left(\delta+4 \delta q^{2}-4 \delta q\right)+\# l^{2}\right. \\
& \left.\left(-3 \delta-7 \delta q^{2}+8 \delta q-2 q+1\right)+\# 1\left(2 \delta+3 \delta q^{2}+2 q^{2}-4 \delta q-1\right)-q^{2}+q \&, 2\right]
\end{aligned}
$$

Proof. Calculated from Mathematica by comparing the voter's utilities from the sincere, unbundled equilibrium tithe partial pandering equilibrium.

Lemma 7. Let there be automatic monitoring and let $R$ be such that unbundled politicians pool and bundled politicians partially pool. Then a bundled politician is better than unbundled politicians for the voter if

$\pi \geq \operatorname{Root}\left[\# 1^{3}\left(\delta+4 \delta q^{2}-4 \delta q\right)+\# 1^{2}\left(-2 \delta-7 \delta q^{2}+6 \delta q-2 q+1\right)+\# 1\left(\delta+3 \delta q^{2}+2 q^{2}-2 \delta q\right)-q^{2} \&, 1\right]$

Proof. Calculated from Mathematica by comparing the voter's utilities from the pandering, unbundled equilibrium tithe partial pandering equilibrium.

\section{B Monitoring}

Lemma 8. Let policies be unbundled. Then if politicians act sincerely, the maximum monitoring cost the voter will pay is $\delta \pi(-2 \pi q+\pi+2 q-1)$. If politicians pool, the maximum monitoring cost the voter will pay is $\pi-q$. 
Proof. The voter's utility from not monitoring is $2 \pi(1+\delta)$. The voter's utility from monitoring is their expected utility from the equilibrium induced by monitoring minus the monitoring cost. First, note that because the politicians ans costs are independent, the voter will either monitor both politicians or neither. Therefore I use the overall expected utility and $2 c$ in the inequalities.

If the politicians act sincerely, the voter will monitor if

$$
\begin{gathered}
2 \pi(\pi(\delta-2 \delta q)+2 \delta q+1)-2 c \geq 2 \pi(1+\delta) \\
c \leq \delta \pi(-2 \pi q+\pi+2 q-1)
\end{gathered}
$$

If the politicians pool, the voter will monitor if

$$
\begin{gathered}
2(q+\delta \pi)-2 c \geq 2 \pi(1+\delta) \\
c \leq q-\pi
\end{gathered}
$$

Lemma 9. Let the policies be bundled. Then if the politician acts sincerely and $\pi \geq \frac{1}{2}$, the maximum monitoring cost the voter will pay is $2 \delta(1-\pi) \pi\left(\pi(1-2 q)^{2}+q(4-3 q)-1\right)$. If the politician acts sincerely and $\pi<\frac{1}{2}$, the maximum monitoring cost the voter will pay is $2 \delta(1-\pi) \pi(2 q-$ 1) $(q-\pi(2 q-1))$. If the politician partial pools, the maximum monitoring cost the voter will pay is $2\left(-2 \pi^{2} q+\pi^{2}+2 \pi q^{2}+\delta(\pi-1) \pi\left(\pi(1-2 q)^{2}+q(2-3 q)-1\right)-\pi-q^{2}+q\right)$. If the politician pools, the maximum monitoring cost the voter will pay is $2(q-\pi)$.

Proof. Similar to the above proof, I simply compare the no monitor utility to the monitored utility for each equilibrium. Details are in Mathematica.

Proposition 7. Assume $\pi \leq q$. Then the voter is always willing to pay more monitor bundled politicians than unbundled politicians.

Proof. I compare the four possible cutoff combinations (Sincere vs Sincere, Sincere vs Partial Pandering, Pandering vs Partial Pandering, and Pander vs Pandering). Assuming $\pi \leq q$, simple algebra 
gives the desired result. 